\title{
Is Laparoscopic Appendicectomy an Acceptable Approach in Management of Patients with Acute Appendicitis?
}

\author{
Ehab Motawa Eisa El-Houseini*, Hussein Ali Abdelmoteleb, Mahmoud S. Ahmed
}

Department of General Surgery, Faculty of Medicine, Aswan University

*Corresponding author: Ehab Motawa Eisa El-Houseini, Mobile: (+20)01113647949, E-Mail: motawea84@gmail.com

\begin{abstract}
Background: Appendicitis is the most common cause of acute abdomen and appendectomy is the most frequent surgical procedure performed in the world in recent times. In the last few years the number of laparoscopic appendectomies performed around the world has dramatically increased.

Objective: The aim of the work is to study the acceptance and satisfaction of the patients as regards the laparoscopic approach for management of acute appendicitis and evaluation the results.

Patients and methods: It was a comparative study included 100 consecutive patients with acute appendicitis. They were given the options to accept the approach for appendectomy whether open or laparoscopic after discussion the advantages and disadvantages of each approach and the last decision were left to the patient. The study was approved by the medical ethics committee of Aswan University Hospital and a written informed consent was obtained from all patients.

Results: The consecutive patients of age ranging from 15-45 years with features suggestive of acute appendicitis were divided into laparoscopic appendectomy group (LA) 70 cases and open appendectomy group (OA) 30 cases, after taking informed consent. LA was done with the help of three trocar/cannulae creating pneumoperitoneum with $\mathrm{CO} 2$ whereas OA was performed by McBurney incision. The operating times in OA and LA were 20-70 minutes (mean 30) and 25-95 minutes (mean 55) respectively. Increased doses of analgesics, antibiotics and antiemetics were required in OA, as compared to LA. The mean postoperative hospital stay in LA group was 1.4 days (range 1-3 days) whereas it was in OA group, it was 3.5 days (range 26 days).

Conclusion: LA is safe and has major benefits like less postoperative pain, decreased wound infection, early hospital discharged, early return to work and a better cosmetic scar than OA.
\end{abstract}

Keywords: Appendicitis, Appendectomy, Laparoscopic appendectomy.

\section{INTRODUCTION}

In 1983, Semm ${ }^{(1)}$ introduced the new laparoscopic technique which replaced the open procedure as the standard practice for several surgical procedures. With the increased interest with this laparoscopic technique, many researches have been studying the outcomes of both the laparoscopic and open appendectomies in order to establish a comparison between the two techniques (1).

Laparoscopic appendectomy showed to be less significantly associated with lower wound infection and post-operative complication rate. Surgical time was considered as a hallmark of technical challenge and resulted diminished in the laparoscopic group. Intra-abdominal abscesses formation rate was higher in the open appendectomy group, although slightly above the statistical significance threshold. Laparoscopic approach seemed to show relevant advantages compared to open appendectomy ${ }^{(2)}$.

The patients with LA experienced prompt postoperative gastrointestinal function recovery in comparison with patients with OA. Furthermore, the immunologic and inflammatory variable white blood cell (WBC) and C-reactive protein (CRP) on postoperative days (POD) 5 was reduced in patients undergone LA compared with that of OA.

A lower overall postoperative complication rate, including surgical wound infection and incision dehiscence was noted in patients with LA compared with $\mathrm{OA}^{(3)}$.

Diagnostic laparoscopy and laparoscopic appendectomy are advisable in case of pregnancy up to 24 weeks. Woman should be under observation of obstetrician-gynecologist in preoperative period to prevent premature birth and abortion ${ }^{(4)}$.

Reduced adhesion formation is a substantive long-term advantage of laparoscopic appendectomy. The adhesion rate after open appendectomy is more than laparoscopic appendectomy which noticed by following up of the patients for three months after surgery ${ }^{(5)}$.

The laparoscopic approach appears to decrease the risk of adhesion formation by $45 \%$ after appendectomy $\quad{ }^{(6)}$ Laparoscopic appendectomy was associated with a 57\% reduction in overall morbidity in all the obese patients. The length of stay was 1.2 days shorter for obese patients undergoing laparoscopic 
appendectomy compared with open appendectomy. In obese patients, laparoscopic appendectomy had superior clinical outcomes compared with open appendectomy ${ }^{(7)}$.

Laparoscopic appendectomy can be wide used in the cases of acute appendicitis, including complications, but it can be restricted in the cases of diffuse peritonitis and appendicular abscesses. This minimally invasive surgical operation allows to reduce significantly the duration of operation, the risk of postoperative complications and the average length of staying in the hospital ${ }^{(8)}$.

\section{AIM OF THE WORK}

To study the acceptance and satisfaction of the patients as regards the laparoscopic approach for management of acute appendicitis and evaluation the results.

\section{PATIENTS AND METHODS \\ Ethical approval:}

This study is accepted by our local committee (Aswan University Ethical Committee) and a written consent was taken from the patients for the operation whether (open or laparoscopic) including possible complications.

Our study included 100 consecutive patients with acute appendicitis. They are given the options to accept the approach for appendectomy whether open or laparoscopic after discussion the advantages and disadvantages of each approach and the last decision were left to the patient. appendicitis.

Inclusion Criteria: patients with acute

Exclusion Criteria: other causes of acute lower abdominal pain.

\section{Patients were subjected to:}

1- Careful history taking specially anorexia, nausea, vomiting, fever and right iliac pain.

2- Full Clinical assessment: General and abdominal examinations were carried out, fever, right lower quadrant tenderness and guarding are usually present.

3- Physical examination.

4- Routine lab investigations such as full blood count, liver function tests, random blood sugar, serum urea and creatinine, bilirubin (total and direct), total protein and albumin, prothrombin time and concentration, INR.

5- Radiological investigations including

- chest X ray

- abdominal ultrasound:

i. Investigations in the form of abdominal ultrasound to assess the tenderness on probing in the right iliac fossa and the presence of right iliac fossa or pelvic collection. Also, to look for the thickened wall prominent of congested appendix and, to exclude any concomitant gynecological finding e.g. tubal pregnancy or ovarian cyst.

Also, to exclude any other cause for right iliac fossa pain, e.g. ileocecal intussusception.

ii. Gynecological consultation was done to female patients to exclude any gynecological cause for the acute lower abdominal pain if the patient's ultrasonography revealed an ovarian cyst or suspected tubal pregnancy.

- CT scan if needed.

- Discussion with the patients about the operation and its complications. All surgeries were carried out under general anesthesia and all surgeries were done by senior surgeon.

\section{All patients were observed for following:}

1- Operative time by minutes from skin incision to wound closure

2- Intraoperative complications, conversion to open procedure, associated pathology and its management.

3- Postoperative complications, postoperative morbidity including wound infection, general complications of surgery, intraperitoneal collection, postoperative hospital stay, postoperative pain (the need for analgesia), and the time needed to return to work.

4- Length of hospital stay.

5- Patient satisfaction.

\section{Patient preparation:}

-All patients were admitted to the appropriate ward via the A \& E, underwent surgery as emergency cases.

-All patients consented to undergo conversion to open appendectomy if necessary.

-All patients received prophylactic antibiotics in the form of $3^{\text {rd }}$ generation cephalosporin.

-cleansing the skin of the umbilicus to prevent postoperative infection.

-All patients had general anesthesia with endotracheal intubation.

-The urinary bladder is catheterized to prevent interference with visualization or inadvertent puncture. 
-Exposure of the abdomen from the level of anterior superior iliac spine to the xiphisternal junction.

-The rest of the body is covered by sterile drapes.

-The skin was prepared with $10 \%$ povidineiodine solution.

\section{METHODOLGY}

\section{Laparoscopic Operative procedure:}

Laparoscopic appendectomies were performed under general anesthesia. After skin preparation, a pneumoperitoneum was created by the use of a Verres needle ${ }^{(9)}$. The needle was introduced in a supraumbilical position with the patient at $10^{\circ}$ Trendelenburg position.

$\mathrm{CO}_{2}$ was insufflated gradually initially using an electronic insufflator (Karl Storz), and the pressure was established at a maximum of $15 \mathrm{~mm}$ $\mathrm{Hg}$. Then the primary trocar $(10 \mathrm{~mm})$ was inserted through the supraumbilical incision. Laparoscopy was then performed with "O" angle viewing laparoscope to ensure the clinical diagnosis and identify the position of the appendix so as to determine the best site of insertion of the other trocars (Fig. 1).

Two more trocars were inserted, one in the left iliac fossa $(5 \mathrm{~mm})$, and the other in the right upper quadrant $(5 \mathrm{~mm})$. This was done lateral to the inferior epigastric vessels.

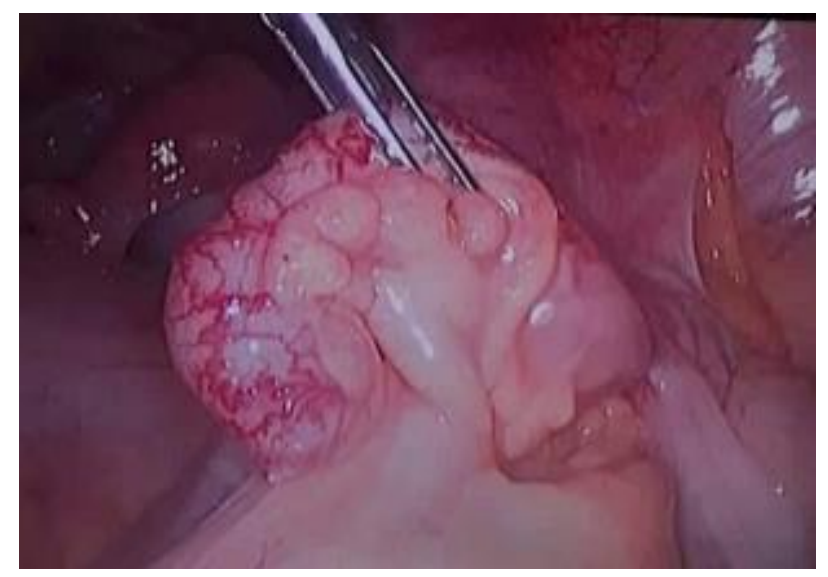

Fig. (1): Identification and grasp the appendix using grasper

Abdominal entry: In our study we used the closed technique to enter the abdomen and create the pneumoperitoneum. However, it is recommended to insert the Veress needle at Palmer's point, just below the left costal margin in the mid-clavicular line In patients with periumbilical adhesions, this site of entry is reportedly safer.
Correct placement is confirmed by demonstrating low pressure and high flow on insufflation. Port placement $10 \mathrm{~mm}$ port is inserted above the umbilicus for the laparoscope. When the Veress needle is used to establish pneumoperitoneum, once the abdomen is insufflated with $\mathrm{CO}_{2}$ to an intra-abdominal pressure of $14 \mathrm{~mm} \mathrm{Hg}$ we insert port $10 \mathrm{~mm}$ and two additional ports may be placed. A $5 \mathrm{~mm}$ port is placed just in the left iliac fossa. Finally, an additional $5 \mathrm{~mm}$ port is inserted in right hypochondrium.

A bowel grasper inserted through the left lower quadrant port can assist with the placement of this last port. On the other hand, placing the left lower quadrant port too far laterally will also pose a problem, as instruments may not reach the appendix. Identifying the appendix is used to visualize the right lower quadrant. As laparoscopy will either confirm the diagnosis or lead to an alternate diagnosis, diagnostic laparoscopy is recommended prior to proceeding to the appendectomy.

Once vascular control has been achieved, any connective or adipose tissue surrounding the appendix should be cleared, leaving the appendix attached only to the base of the cecum. Amputation and removal of the appendix dividing the appendix using vicryl $2 / 0$ sutures to amputate the appendix, endoloops consisting of a heavy absorbable suture may be used. Two sutures are placed proximally and a third one is placed about $1 \mathrm{~cm}$ distally. The loops should be cinched firmly around the appendix, without tearing through it (Fig. 2).

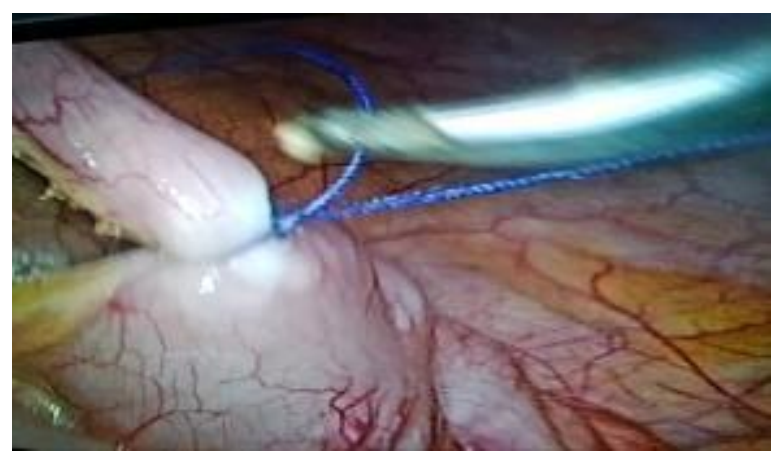

Fig. (2): Laparoscopic appendectomy using ligature

An alternative to endoloop is using a metal clips $(10 \mathrm{~mm})$ in which we use one clip proximally and two distally then dissect the appendix (Fig. 3, 4, 5). 


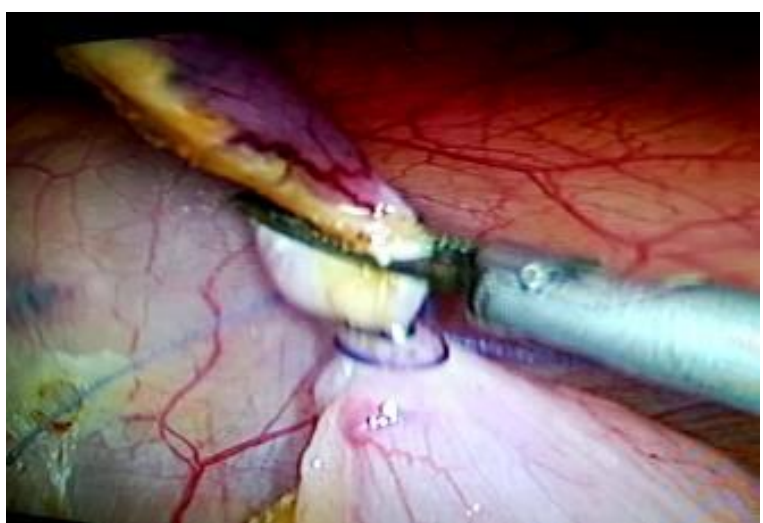

Fig. (3): Laparoscopic appendectomy using metallic clip.

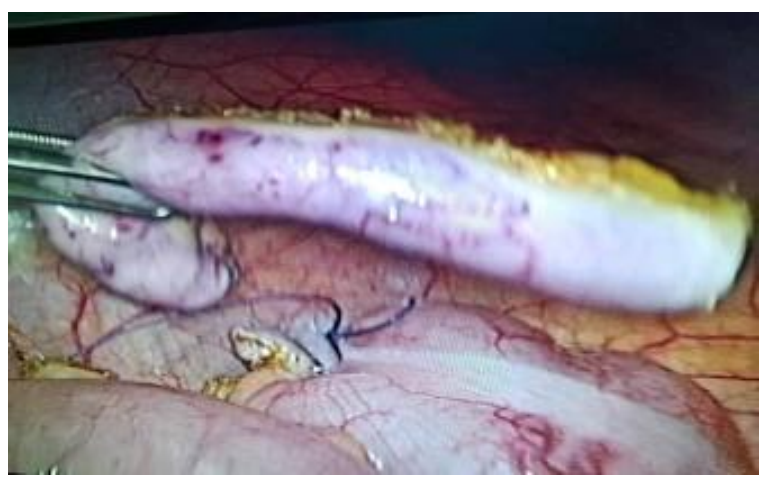

Fig. (4): Laparoscopic appendectomy.

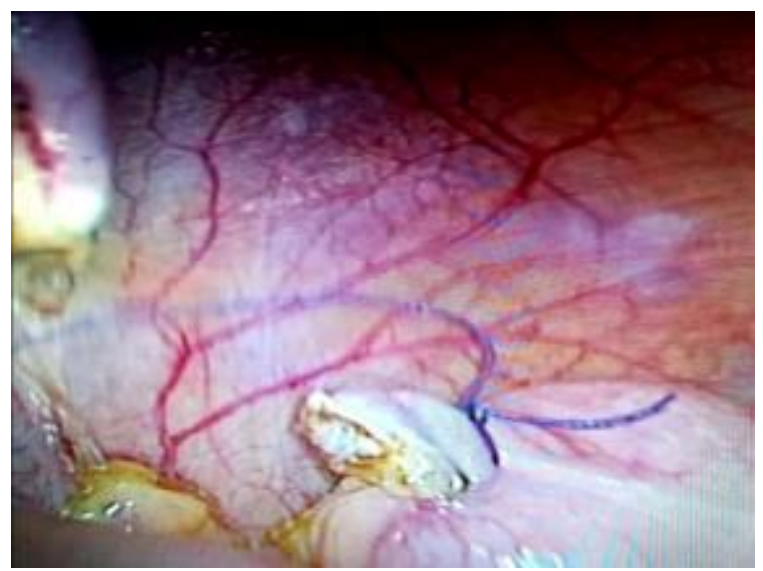

Fig. (5): The Stump of the appendix after appendectomy.

If endoloops are used, the appendix is cut with laparoscopic scissors just below the distal endoloop.

The appendix is removed from the abdomen in an extraction bag.

It is important that feculent contents are not spilled during this step and that the appendix does not touch the wound during the extraction process, as that contributes to higher rates of intra-abdominal and wound infections.

The appendix is removed through the umbilical port. This can be done by switching the laparoscope to the suprapubic site and using a claw grasper to grab the endobag through the umbilical site. Closure If purulent fluid is seen in the right lower quadrant, it should be aspirated and lavage performed.

All port sites should be removed under direct visualization to ensure good hemostasis. This is particularly important in the left lower quadrant where the inferior epigastric vessels may be injured.

The abdomen is desufflated and all ports are removed. The fascial defects should be closed at the $10 \mathrm{~mm}$ port sites using absorbable heavy sutures placed in a figure-of-eight manner.

The skin can be closed with running subcuticular sutures. Formation the decision of using the suture or clips was taken according to the base of appendix.

The clips is used when the base of the appendix is not wide or thick, and the decision was taken visually and that for the safety of the patient.

\section{Open operative procedure:}

The patient was placed in the supine position and underwent general anesthesia with endotracheal intubation. While the patient was anesthetized and the abdominal musculature relaxed, the patient's abdomen was carefully examined. The skin incision on McBurney's point was carried through the subcutaneous tissue until the external oblique fascia was exposed.

A small incision was made in the external oblique fascia along the line of its fibers. This incision was sharply extended with scissors along the direction of the fibers. The underlying fibers of the internal oblique muscle and the transversus abdominis muscle were identified, split and retracted along the direction of their fibers. Next, retractors were adjusted to expose the peritoneum. Then grasping the peritoneum with clamps was done, carefully verifying that intra-abdominal viscera had not been inadvertently grasped. A small incision was made in the peritoneum by scissors.

The cecum was delivered into the field gently grasping the cecum with moistened gauze and delivering it into the wound using a rocking movement and the anteriortenia of the cecum was followed till identification of appendix. Medial mobilization of the cecum was done bluntly with a finger combined with sharp or electrocautry in cases of difficult retrocal appendix (Fig. 6). 


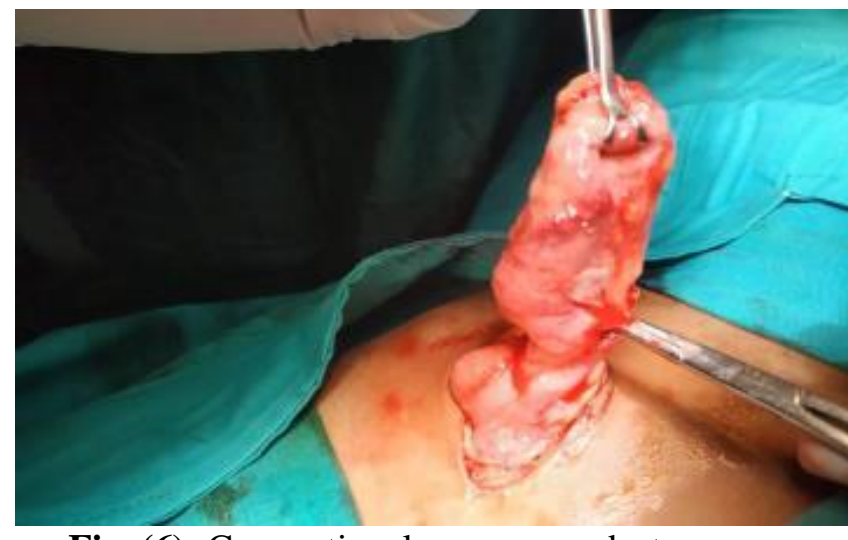

Fig. (6): Conventional open appendectomy.

The mesoappendix was divided between clamps and ligated with an absorbable suture. The base of the appendix was divided and ligated with absorbable suture material. Purse string sutures were done in cases of inflamed base of the appendix.

The mucosa was obliterated to avoid the development of mucocele. The wound was closed in layers. If perforation or gangrene were present, the skin and subcutaneous tissue closure was by widely spaced sutures.

\section{Statistical analysis:}

Recorded data were analyzed using the statistical package for social sciences, version 20.0 (SPSS Inc., Chicago, Illinois, USA). Quantitative data were expressed as mean \pm standard deviation (SD).
Qualitative data were expressed as frequency and percentage.

\section{The following tests were done:}

- Independent-samples t-test of significance was used when comparing between two means.

- Chi-square $\left(\mathrm{x}^{2}\right)$ test of significance was used in order to compare proportions between two qualitative parameters.

- The confidence interval was set to $95 \%$ and the margin of error accepted was set to $5 \%$. The pvalue was considered significant as the following:

- Probability (P-value)

- P-value <0.05 was considered significant.

- P-value <0.001 was considered as highly significant.

- P-value >0.05 was considered insignificant.

\section{RESULTS}

\section{Patients questionnaire}

Patients were given the options to accept the approach for appendectomy whether open or laparoscopic after discussion the advantages and disadvantages of each approach and the last decision were left to the patient.

The patient's ages ranged from $(25-71)$ years with median age $33(29-46.5)$ years in whole patients as shown in Table 1.

Table 1: Demographic data for the whole group.

\begin{tabular}{|c|c|c|c|c|}
\hline 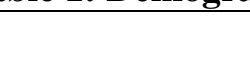 & & Mean / N & SD / \% & Median (IQR) \\
\hline \multirow{2}{*}{ Surgery Type } & Open Surgery & 30 & $30 \%$ & \\
\hline & Laparoscopic surgery & 70 & $70 \%$ & \\
\hline \multirow{3}{*}{ Sex } & Age & 38.5 & 13.14 & $33(29-46.5)$ \\
\hline & Male & 28 & $28 \%$ & \\
\hline & Female & 72 & $72 \%$ & \\
\hline
\end{tabular}

\section{Patient's characteristics}

The patient's ages ranged from 25-34 years with median age 30 years and mean age 29.83 years in open surgery group as shown in Table 2.

The patient's ages ranged from 25-71 years with median age 36.5 years and mean age 42.21 years in laparoscopic surgery group as shown in Table 2. 
Table 2: Age distribution in the 2 groups (100 patients)

\begin{tabular}{|c|c|c|c|c|c|c|c|}
\hline & \multicolumn{4}{|c|}{ Surgery Type } & \multirow{2}{*}{\multicolumn{2}{|c|}{$\begin{array}{c}\text { Student } \\
\text { t-test }\end{array}$}} \\
\hline & & \multicolumn{2}{|c|}{ Open Surgery } & \multicolumn{2}{|c|}{ Laparoscopic Surgery } & & \\
\hline & & Mean N & $\begin{array}{c}\text { SD \% } \\
\text { (of Column) }\end{array}$ & Mean N & $\begin{array}{l}\text { SD\% (of } \\
\text { Column) }\end{array}$ & PV & Sig \\
\hline & ge & 29.83 & 2.95 & 42.21 & 14.05 & $<0.001$ & $S$ \\
\hline \multirow[t]{2}{*}{ Sex } & Male & 14 & $46.7 \%$ & 14 & $20 \%$ & \multirow[t]{2}{*}{$0.006(\mathbf{C})$} & \multirow[t]{2}{*}{ S } \\
\hline & Female & 16 & $53.3 \%$ & 56 & $80 \%$ & & \\
\hline
\end{tabular}

(C) Chi-square test of significance.

\section{Operative time}

The operative time was significantly longer in the laparoscopic group with mean time 55.9 minutes than open group with mean time 24.27 min $P$ value was less than 0.001 as shown in Table 3 .

Table 3: Operative time of all patients

\begin{tabular}{|l|c|c|c|c|c|c|}
\hline \multirow{1}{*}{} & \multicolumn{4}{|c|}{ Surgery Type } & \multicolumn{2}{c|}{ Chi Square test } \\
\cline { 2 - 6 } & \multicolumn{2}{|c|}{ Open Surgery } & \multicolumn{2}{c|}{ Laparoscopic Surgery } & PV & Sig \\
\cline { 2 - 7 } & $\begin{array}{c}\text { Mean } \\
\text { Median N }\end{array}$ & $\begin{array}{c}\text { SD } \\
\text { (IQR)\% } \\
\text { (of Row) }\end{array}$ & $\begin{array}{c}\text { Mean } \\
\text { Median N }\end{array}$ & $\begin{array}{c}\text { SD } \\
\text { (IQR)\% } \\
\text { (of Row) }\end{array}$ & & \\
\hline Operative time & 24.27 & 3.44 & 55.90 & 9.74 & $<0.001($ T) & S \\
\hline
\end{tabular}

Intra operative Complications

(T) Student t-test of significance.

Blood loss

The blood loss was not significant in both groups where the $P$ value 0.419 as shown in Table 4 .

Table 4: Blood Loss of all cases

\begin{tabular}{|c|c|c|c|c|c|c|}
\hline \multirow{2}{*}{} & \multicolumn{4}{|c|}{ Surgery Type } & \multicolumn{2}{c|}{ Chi Square test } \\
\cline { 2 - 7 } & \multicolumn{2}{|c|}{ Open Surgery } & Laparoscopic Surgery & PV & Sig \\
\cline { 2 - 7 } & $\begin{array}{c}\text { Mean } \\
\text { Median N }\end{array}$ & $\begin{array}{c}\text { SD } \\
\text { (IQR)\% } \\
\text { (of Row) }\end{array}$ & $\begin{array}{c}\text { Mean } \\
\text { Median N }\end{array}$ & $\begin{array}{c}\text { SD } \\
\text { (IQR)\% } \\
\text { (of Row) }\end{array}$ & & \\
\hline Blood loss & 15.55 & $(5-20.8)$ & 10.00 & $(5-19.3)$ & 0.419 (M) & NS \\
\hline
\end{tabular}

(M) Mann-Whitney test of significance.

In Group (Lap): 2 complications were met,

- Bleeding from mesoappendix which was controlled by clips.

- Bleeding after puncture of ovarian cyst which was controlled by diathermy.

In Group (Open): 2 complications were met,

- One case with caecal serosal tears which were repaired primarily by absorbable sutures.

- One case of iatrogenic ovarian injury which was also repaired primarily by absorbable sutures. 
Associated pathology and its management In Group (Lap):

- Two cases of right ovarian cysts were found, one was punctured and the other left with no intervention according to gynecological consultation which was done intraoperatively.

- One case of peri-ovarian collection mostly due to ruptured Graafian follicle (Mittelschmerz).

\section{In Group (Open):}

- One case of hemoperitoneum was found and lower midline approach was adopted which revealed ovarian endometriosis so excision of the ectopic tissue was performed.

\section{Conversion of laparoscopic procedure to open}

- One case of laparoscopic appendectomy was converted to open procedures, it was a case of ruptured ectopic pregnancy (right salpingo-oophrectomy was done) with intervention according to gynecological consultation which was done intraoperatively.

\section{Post-operative complications}

- The overall post-operative complications in the 2 groups are shown in Table $\mathbf{5}$.

Table 5: Postoperative complications

\begin{tabular}{|c|c|c|c|c|c|c|c|}
\hline & \multicolumn{4}{|c|}{ Surgery Type } & \multirow{2}{*}{\multicolumn{2}{|c|}{ Chi-Square test }} \\
\hline & & \multicolumn{2}{|c|}{ Open Surgery } & \multicolumn{2}{|c|}{ Laparoscopic Surgery } & & \\
\hline & & No & \% (of Row) & $\mathbf{N}$ & \% (of Row) & P-Value & Sig. \\
\hline \multirow{4}{*}{ Pain } & 1 & 9 & $16.7 \%$ & 45 & $83.3 \%$ & \multirow[t]{4}{*}{$0.004^{(\mathrm{F})}$} & \multirow[t]{4}{*}{$\mathrm{S}$} \\
\hline & 2 & 13 & $41.9 \%$ & 18 & $58.1 \%$ & & \\
\hline & 3 & 8 & $57,1 \%$ & 6 & $42.9 \%$ & & \\
\hline & 4 & 0 & $0.0 \%$ & 1 & $100.0 \%$ & & \\
\hline \multirow[t]{2}{*}{ Fever } & NO & 22 & $29.7 \%$ & 52 & $70.3 \%$ & \multirow[t]{2}{*}{0.921} & \multirow[t]{2}{*}{$\mathbf{N S}$} \\
\hline & Yes & 8 & $30.8 \%$ & 18 & $69.2 \%$ & & \\
\hline \multirow[t]{2}{*}{ Vomiting } & NO & 21 & $31.3 \%$ & 46 & $68.7 \%$ & \multirow[t]{2}{*}{0.676} & \multirow[t]{2}{*}{$\mathbf{N S}$} \\
\hline & Yes & 9 & $27.3 \%$ & 24 & $72.7 \%$ & & \\
\hline \multirow[t]{2}{*}{ Respiratory Tract } & NO & 23 & $29.9 \%$ & 54 & $70.1 \%$ & \multirow[t]{2}{*}{0.959} & \multirow[t]{2}{*}{$\mathbf{N S}$} \\
\hline & Yes & 7 & $30.4 \%$ & 16 & $69.6 \%$ & & \\
\hline \multirow[t]{2}{*}{ Wound infection } & NO & 18 & $21.7 \%$ & 65 & $78.3 \%$ & \multirow[t]{2}{*}{$<0.001$} & \multirow[t]{2}{*}{$\mathbf{S}$} \\
\hline & Yes & 12 & $70.6 \%$ & 5 & $29.4 \%$ & & \\
\hline \multirow[t]{2}{*}{ Paralytic ileus } & NO & 22 & $27.2 \%$ & 59 & $72.8 \%$ & \multirow[t]{2}{*}{0.201} & \multirow[t]{2}{*}{$\overline{\mathbf{N S}}$} \\
\hline & Yes & 8 & $42.1 \%$ & 11 & $57.9 \%$ & & \\
\hline \multirow[t]{2}{*}{ Constipation } & NO & 22 & $25.3 \%$ & 65 & $74.7 \%$ & \multirow[t]{2}{*}{$0.0190^{(\mathrm{F})}$} & \multirow[t]{2}{*}{$\mathbf{S}$} \\
\hline & Yes & 8 & $61.5 \%$ & 5 & $38.5 \%$ & & \\
\hline \multirow[t]{2}{*}{ U. retention } & NO & 20 & $25.0 \%$ & 60 & $75.0 \%$ & \multirow[t]{2}{*}{0.029} & \multirow[t]{2}{*}{$\mathbf{S}$} \\
\hline & Yes & 10 & $50.0 \%$ & 10 & $50.0 \%$ & & \\
\hline
\end{tabular}

(F) Fisher's Exact test of significance.

Overall post-operative complications showed no significant difference between the two groups with $P V(0.201-0.959)$ regarding Fever, Vomiting and Respiratory tract infection, Paralytic ileus. However, postoperative complications regarding Pain, wound infection were significantly higher in the open group than the Laparoscopic group. (70.6\% infected in open cases and $29.4 \%$ infected in laparoscopic cases) with P-Value $<0.001$. 
Administration of Antibiotics and Analgesic Post-operative:

Antibiotics: The antibiotic administration was slightly increased in the open group compared with the laparoscopic group as shown in Table 6.

Analgesic: The analgesic administration was not significantly used in both groups as shown in Table 6.

Anti-emetics: The anti-emetics administration was not significantly used in both groups as shown in Table 6.

Table 6: Post-operative medications of all cases

\begin{tabular}{|c|c|c|c|c|c|c|c|}
\hline \multirow{3}{*}{\multicolumn{2}{|c|}{ 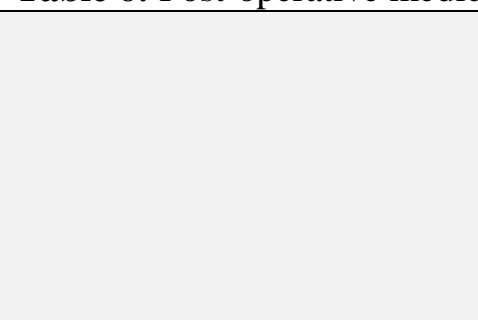 }} & \multicolumn{4}{|c|}{ Surgery type } & \multicolumn{2}{|c|}{$\begin{array}{c}\text { Chi Square } \\
\text { test }\end{array}$} \\
\hline & & \multirow{2}{*}{$\begin{array}{c}\text { Open } \\
\text { Surgery } \\
\text { Mean } \\
\text { Median N }\end{array}$} & \multicolumn{3}{|c|}{ Laparoscopic Surgery } & \multirow[t]{2}{*}{ PV } & \multirow[t]{2}{*}{ Sig } \\
\hline & & & $\begin{array}{c}\text { SD } \\
\text { (IQR)\% } \\
\text { (of Row) }\end{array}$ & $\begin{array}{c}\text { Mean } \\
\text { Median N }\end{array}$ & $\begin{array}{c}\text { SD } \\
\text { (IQR)\% } \\
\text { (of Row) }\end{array}$ & & \\
\hline \multirow[t]{2}{*}{ Anti-biotics } & No & 6 & $10.9 \%$ & 49 & $89.1 \%$ & \multirow[t]{2}{*}{$<0.001$} & \multirow[t]{2}{*}{ S } \\
\hline & Yes & 24 & $53.3 \%$ & 21 & $46.7 \%$ & & \\
\hline \multirow[t]{2}{*}{ Analgesics } & NSAID & 22 & $26.8 \%$ & 60 & $73.2 \%$ & \multirow[t]{2}{*}{0.14} & \multirow[t]{2}{*}{ NS } \\
\hline & NSAID+ OP & 8 & $44.4 \%$ & 10 & $55.6 \%$ & & \\
\hline \multirow{2}{*}{$\begin{array}{l}\text { Anti- } \\
\text { emetics }\end{array}$} & No & 21 & $29.6 \%$ & 50 & $70.4 \%$ & \multirow[t]{2}{*}{0.885} & \multirow[t]{2}{*}{ NS } \\
\hline & Yes & 9 & $31 \%$ & 20 & $69 \%$ & & \\
\hline
\end{tabular}

\section{Length of hospital stay:}

The mean postoperative hospital stay in laparoscopic group was 1.6 days, whereas in open group, it was 2.83 days, that means there was a significant increase in hospital stay in the open group compared with laparoscopic group as shown in Table 7. There were not major complications in both groups like fecal fistula, pelvic abscess or incisional / port-site hernia. The condition of scar was better in laparoscopic group.

Table 7: Hospital stay and time taken to return to normal activity

\begin{tabular}{|c|c|c|c|c|c|c|}
\hline \multirow{2}{*}{} & \multicolumn{4}{|c|}{ Surgery Type } & \multicolumn{2}{c|}{ Mann-Whitney test } \\
\cline { 2 - 7 } & Open Surgery & \multicolumn{2}{|c|}{ Laparoscopic Surgery } & Sig \\
\cline { 2 - 7 } & Mean/ Median & $\begin{array}{c}\text { SD } \\
\text { (IQR) } \\
\text { \% } \\
\text { (of Row) }\end{array}$ & $\begin{array}{c}\text { Mean/ } \\
\text { Median }\end{array}$ & $\begin{array}{c}\text { SD } \\
\text { (IQR) } \\
\text { \% } \\
\text { (of Row) }\end{array}$ & PV & \\
\hline Hospital Stay & $2.83 / 2$ & $(1-3)$ & $1.6 / 1$ & $(1-2)$ & 0.005 & S \\
\hline
\end{tabular}

\section{DISCUSSION}

In our study included 100 consecutive patients with acute appendicitis. Those patients are given the options to accept the approach for appendectomy whether open or laparoscopic after discussion the advantages and disadvantages of each approach and the last decision will be left to the patient.

The use of metallic clips for the closure of appendix stump was first described by Cristalli et al. ${ }^{(10)}$ but they has not gained broad acceptance for the closure of appendix stump. The mean operative time on open and laparoscopic were (24.27 / 55.9 minutes) respectively. The wound and intraabdominal infection rates were $70.6 \%$ and $29.4 \%$, respectively. There were not major complications in both groups like fecal fistula, pelvic abscess or incisional / port-site hernia. Only of laparoscopic appendectomy was converted to open procedures, it was a case of ruptured ectopic pregnancy (right salpingo-oophrectomy was done) with intervention according to gynecological consultation so conversion rate was $1.43 \%$.

In our study, the operative time was significantly longer in the laparoscopic group with mean time 55.9 minutes than open group with mean time $24.27 \mathrm{~min} P$ value was less than 0.001 .

Regarding pain and wound infection, they were significantly higher in the open group than the Laparoscopic group (70.6\% infected in open cases and $29.4 \%$ infected in laparoscopic cases) with $P$ Value $<0.001$.

There were no significant difference between the two groups with $P V(0.201-0.959)$ 
regarding fever, vomiting and respiratory tract infection, Paralytic ileus and hospitalization time.

Several authors proposed that the new technique of laparoscopic appendectomy should be the preferred treatment for acute appendicitis. However, unlike laparoscopic cholecystectomy, laparoscopic appendectomy has not yet gained popularity. Laparoscopic cholecystectomy is now considered a standard method of performing cholecystectomy and has mostly replaced the old method throughout the world, while appendectomy has yet to achieve such popularity ${ }^{(11)}$.

Although there is no consensus with regard to the advantages of the laparoscopic approach compared to the conventional technique, the use of laparoscopic appendectomy has increased significantly in the last several years.

In the present study, we were able to demonstrate the superiority of the laparoscopic approach in terms of hospital stay and wound infection, with only marginally higher hospital costs. Although the incidence of intra-abdominal abscess formation was higher after laparoscopic appendectomy, all complications occurred early in our practice. Greater experience and improvements in our technique has made it possible to eradicate this catastrophic complication ${ }^{(\mathbf{1 2})}$.

Laparoscopic appendectomy has emerged as a safe procedure, and its potential advantages of shorter hospital stay, early mobilization, early return of bowel function, acceptable complication rate along with the recent enthusiasm of minimally invasive surgery, has led some authors to advocate this approach as the procedure of choice for uncomplicated appendicitis ${ }^{(\mathbf{1 3})}$.

The role of laparoscopic appendectomy has not yet been clearly defined. Numerous factors need to be considered in deciding the ideal, and most appropriate surgical technique for acute appendicitis.

Meroao et al. ${ }^{(14)}$ who studied a total of 50 patients: 25 (open appendectomy group) and 25 (laparoscopic group), showed that the mean operative time for the laparoscopic group was significantly longer (79.6 $\mathrm{min}$ ) than the open group (53.4 min) with $P<0.0001$.

Similarly, Dai and Shuai ${ }^{(15)}$ show metaanalysis of operation time showed that LA took longer than OA by $11.59 \mathrm{~min}(\mathrm{WMD}=11.59,95 \%$ CI: $6.65-16.53, p<0.00001)$. Considering the increased instrumentation used during laparoscopic surgery and the setup time involved, the concept of a laparoscopic procedure taking longer than its open equivalent is not surprising; however, the slightly longer operation time with the additional 11.59 min in LA will most probably be reduced over time, as surgeons become more adept at the procedure.

Another study done by Katkhouda $\boldsymbol{e t}$ al. (12) showed that the operative time was significantly longer in the laparoscopic group (80 minutes versus 60 minutes with $P=0.000$.

All the previous results of mentioned studies regarding operative time are comparable to this study as this study revealed that there was a significant difference regarding operative time with $P V<0.001$ (mean time was 55.9 minutes in the laparoscopic group and 24.27 minutes in the open group).

The postoperative pain is usually troublesome for the patients. In a study done by Long et al, (16) patients who had laparoscopic appendectomy required less parenteral analgesia than open-surgery patients (1.6 versus 2.2 days' worth; $33.3 \mathrm{mg}$ versus $53.5 \mathrm{mg}$ of morphine or equivalent; $P<0.001$ for both measures).

All the previous results regarding the postoperative pain can be compared to the present study as there were less post-operative pain in laparoscopic group. The difference was significant $(P V=0.004)$.

On the other hand, the study done by Katkhouda et al. ${ }^{(12)}$ showed that the severity of pain experienced and its influence on activity were similar for both groups. Narcotic medication usage to control postoperative pain was also equivalent between the 2 groups which can be compared to this study. These results may be related to different pain threshold and different pain perception among the studied groups of different authors.

In all laparoscopic surgeries, the hospital stay after laparoscopic appendectomy was significantly lower than after open appendectomy in all of the reported studies.

In a study done by Guller et al. (17) laparoscopic appendectomy was associated with shorter median hospital stay (laparoscopic appendectomy: 2.06 days, open appendectomy: 2.88 days, $P<0.0001$ ).

Another study done by Yau et al. (18) revealed that mean hospital stay was 5 days and 6 days for LA and OA group respectively $(P<0.001)$.

In the work of Carbonell et al. ${ }^{(19)}$, the hospital stay was significantly lower in the laparoscopic group (mean hospital stay was 27.2 hours) compared to the open group (53.1 hours), $(P=0.001)$.

All previous results of mentioned studies regarding hospital stay are comparable to this study as this study revealed that there was a significant increase in hospital stay in the open group (mean hospital stay was 2.83 days), than the laparoscopic group (mean hospital stay was 1.6), $(P V=0.005)$. 
A study by Yau et al. (18) was done to evaluate wound infection. The results showed that there was one patient converted to OA $(0.6 \%)$ in the LA group who suffered from wound infection, and there were seven (10\%) wound infections in the OA group $(P=0.001)$.

Sauerland et al. ${ }^{(20)}$ who included 67 studies, of which 56 compared laparoscopic appendectomy (with or without diagnostic laparoscopy) versus open appendectomy in adults found that wound infections were less likely after laparoscopic than after open appendectomy.

All previous results of mentioned studies regarding wound infection are comparable to this study as this study revealed that there was a significant decrease in wound infection in laparoscopic group $(P V<0.001)$.

Sauerland et al. ${ }^{(20)}$ showed that diagnostic laparoscopy reduced the risk of a negative appendectomy, but this effect was stronger in fertile women (relative risk 0.20; confidence interval 0.11 to 0.34 ) as compared to unselected adults (relative risk 0.37; confidence interval 0.13 to 1.01$)$.

One study was done in Dublin on 100 premenopausal women who were admitted with abdominal pain. After final assessment, patients were placed in following diagnostic categories; gynecological (30\%); nonspecific abdominal pain (29\%); acute appendicitis (23\%); renal (9\%) and miscellaneous (9\%).The mean duration of hospital stay for patient with nonspecific abdominal pain was 67 days and one third of these patients, underwent appendectomy for normal appendix Abdominal pain in premenopausal women is often psychosomatic and the laparoscopic intervention may be considered in these women with nonspecific pain abdomen to prevent removal of a normal appendix ${ }^{(21)}$.

However, this last sentence of O'Byrne et al. (21) (to prevent removal of a normal appendix) is not agreed by most of the authors because the normal appendix should be removed: first, to be biopsied and the second cause to eliminate acute appendicitis from the differential diagnosis of subsequent abdominal pain ${ }^{(22,23)}$.

In this study: laparoscopy revealed gynecological pathology in four patients, most of them were dealt with laparoscopically. This figure approaches that of (gynecological pathology was $30 \%)^{(21)}$.

While in open procedure, the associated pathology was found in one case of hemoperitoneum was found and lower midline approach was adopted which revealed ovarian endometriosis so excision of the ectopic tissue was performed under gynecological consultation. These results clarify the importance of laparoscopy as a diagnostic and therapeutic tool to deal with other causes of acute abdomen.

This advantage permits the surgeons to manage even gynecological cases without extending or changing incisions with the least postoperative complications.

\section{CONCLUSION}

The majority of cases whose accepted laparoscopic surgery were satisfied with results as it showed on this study that the laparoscopic surgery is more safe and has a major benefits like less postoperative pain, decreased wound infection, early hospital discharged, early return to work and a better cosmetic scar.

\section{REFERENCES}

1. Semm K (1983): Endoscopic Appendectomy. Endoscopy, 15 (2):59-64.

2. Ciarrocchi A, Gianfranco A (2014): Laparoscopic versus open appendectomy in obese patients: A Meta-Analysis of Prospective and Retrospective Studies. Journal of Minimal Access Surgery, 10 (1): 4-9.

3. Lee SL, Hung SH (2006): Acute appendicitis: Is there a difference between children and adults? The American Surgeon, 72 (5):409-13.

4. Panin AV, Dubrovsky A, Petrov $Y$ et al. (2016): The results of open and laparoscopic appendectomy in pregnant women with acute appendicitis. Eur $\mathbf{J}$ Obstet Gynecol Reprod Biol., 4: 21-5.

5. Isaksson $\mathrm{K}$, Agneta $\mathrm{M}$, Ann-Cathrin $\mathrm{M}$ et al. (2014): Long-term follow-up for adhesive small bowel obstruction after open versus laparoscopic surgery for suspected appendicitis. Annals of Surgery, 259(6): 1173-7.

6. Ouaissi M, Gaujoux $S$, Veyrie $N$ et al. (2012): Post-operative adhesions after digestive surgery: Their incidence and prevention: Review of the Literature. Journal of Visceral Surgery, 149 (2): 104-14.

7. Mason RJ, Ashkan M, Jolene RM et al. (2012): Laparoscopic vs open appendectomy in obese patients: Outcomes using the American College of Surgeons National Surgical Quality Improvement Program Database. Journal of the American College of Surgeons, 215 (1):88-100.

8. Kooij IA, Sahami S, Meijer S et al. (2016): The immunology of the vermiform appendix: A Review of literature. Clinical and Experimental Immunology, 186 (1):1-9.

9. Heneghan S, Myers J, Fanelli $R$ et al. (2009): Society of American Gastrointestinal Endoscopic Surgeons (SAGES) guidelines for office endoscopic services. Surgical Endoscopy, 23(5):1125-9.

10. Cristalli BG, Izard V, Jacob F et al. (1991): Laparoscopic appendectomy using a clip applier. Surgical Endoscopy, 5 (4): 176-78. 
11. Peiser JG, Greenberg D (2002): Laparoscopic versus open appendectomy: Results of a retrospective comparison in an Israeli Hospital. The Israel Medical Association Journal, 4 (2): 91-94.

12. Katkhouda N, Rodney JM, Shirin T et al. (2005): Laparoscopic versus open appendectomy: A prospective randomized double-blind study. Annals of Surgery, 242 (3): 439-50.

13. Tarnoff M, Atabek U, Goodman M et al. (1998): A comparison of laparoscopic and open appendectomy. Journal of the Society of Laparoendoscopic Surgeons, 2 (2): 153-58.

14. Meroao A (1999): Laparoscopic versus open appendectomy. J KAU., 7 (1): 85-91.

15. Dai L, Jian S (2017): Laparoscopic versus open appendectomy in adults and children: A metaanalysis of randomized controlled trials. United European Gastroenterology Journal, 5 (4): 542-53.

16. Long KH, Bannon MP, Zietlow SP et al. (2001): A prospective randomized comparison of laparoscopic appendectomy with open appendectomy: Clinical and economic analyses. Surgery, 129 (4): 390-400.

17. Guller U, Sheleika H, Harriett $P$ et al. (2004): Laparoscopic versus open appendectomy: Outcomes comparison based on a large administrative database. Annals of Surgery, 239 (1): 43-52.

18. Yau KK, Wing TS, Chun NT et al. (2007): Laparoscopic versus open appendectomy for complicated appendicitis. Journal of the American College of Surgeons, 205 (1): 60-65.

19. Carbonell AM, Justin MB, Amy EL et al. (2004): Outcomes of laparoscopic versus open appendectomy. The American Surgeon, 70 (9): 756-59.

20. Sauerland S, Thomas J, Edmund AN (2010): Laparoscopic versus open surgery for suspected appendicitis. The Cochrane Database of Systematic Reviews, 10: CD001546.

21. O'Byrne JM, Dempsey CB, O'Malley MK et al. (1991): Non-specific abdominal pain in premenopausal women. Irish Journal of Medical Science, 160 (11): 344-46.

22. Mishra RK, Hanna GB, Cuschieri A (2008): Laparoscopic versus open appendectomy for the treatment of acute appendicitis. World J. of Laparoscopic Surgery, 1 (1): 19-28.

23. Kehagias I, Stavros NK, Spyros P et al. (2008): Laparoscopic versus open appendectomy: which way to go? World Journal of Gastroenterology, 14 (31):4909-14. 